\title{
Vaginal Progesterone versus Cervical Cerclage to Prevent Preterm Birth
}

Mohammed Amin Fahmy ${ }^{1, *}$ MSc., Abdallah Khalil Eissa ${ }^{1}$ MD., Alrefaai Abd El- Fattah Marie ${ }^{1}$ MD.

\author{
* Corresponding Author: \\ Mohammed Amin Fahmy \\ Muhammed_amin24@yahoo.com
}

Received for publication June 21, 2021; Accepted August 29, 2021; Published online August 29, 2021.

Copyright The Authors published by Al-Azhar University, Faculty of Medicine, Cairo, Egypt. Users have the right to read, download, copy, distribute, print, search, or link to the full texts of articles under the following conditions: Creative Commons Attribution-Share Alike 4.0 International Public License (CC BY-SA 4.0)

doi: 10.21608/aimj.2021.79210.1492

${ }^{1}$ Department of Obstetrics and Gynecology, Faculty of Medicine, AlAzhar University, Cairo, Egypt.

\begin{abstract}
Background: In spite the fact that the prevalence of preterm birth has increased, several treatments have been identified as having a possible role in reducing the risk of repeated preterm birth (PTB), such as bed rest and vaginal progesterone, which have been tried to ameliorate this distressing condition.

Objective: To compare the efficacy of vaginal progesterone and cerclage in preventing preterm birth.

Patients and Methods: This study was a prospective cohort randomized clinical study that was conducted on 120 pregnant women at high risk of preterm birth; 60 cases were prescribed vaginal progesterone and the remaining 60 cases underwent cervical cerclage. They were all chosen from the outpatient clinics at $\mathrm{Al}$-Hussien university Hospital and $\mathrm{Kafr}$ EL- Sheikh General Hospital during the period from March 2020 till December 2020.

Results: It was observed that in cases who received vaginal progesterone the mean gestational age was $(35.76 \pm 2.33$ weeks $)$ while it was $(36.32 \pm 2.12$ weeks) in those who underwent cerclage. The mean gestational age improved in the cerclage groups by about 3.92 days. The gestational age at delivery was higher in the cerclage group than that in the progesterone group, but without significant difference. As regard neonatal outcome of the current delivery, the overall morbidity was shown in 22 cases (19.8\%) and mortality was $5(4.5 \%)$.

Conclusion: Both vaginal progesterone as well as cervical cerclage had a significant beneficial impact in opposition to preterm delivery and improving perinatal consequences among the high-risk singleton pregnant ladies with former spontaneous PTB.
\end{abstract}

Keywords: Preterm birth; Progesterone; Cervical cerclage.

Disclosure: The authors have no financial interest to declare in relation to the content of this article. The Article Processing Charge was paid for by the authors.

Authorship: All authors have a substantial contribution to the article.

\section{INTRODUCTION}

Preterm birth (PTB), defined as birth before the 37th week of pregnancy, is a serious perinatal health issue. It is implicated in 75 percent of prenatal deaths and more than half of long-term neurological impairments, and it is the second most common cause of death in children under the age of five. ${ }^{1}$ Preterm births are on the rise in many countries across the world, and they have become a global health concern that is expected to skyrocket over the next decade. ${ }^{2}$ The increasing rise in preterm births is concerning, as more than 1 million infants die each year as a result of problems caused by premature delivery. ${ }^{3}$

Various treatments have been identified as having a possible role in reducing the likelihood of repeated preterm birth (PTB). ${ }^{4}$

Bed rest and vaginal progesterone have been tried to ease this bothersome condition, but only cerclage has been proven to enhance the mechanical and functional length of the cervix, thereby contributing to the reduction of PTB. Cervical shortening alone or in twin gestation with or without a short cervix, excluding instances with an associated cervical length (CL) of less than $15 \mathrm{~mm}$ and/or cervical dilatation more than $10 \mathrm{~mm}$, cerclage is not acceptable for all therapeutic situations. ${ }^{5}$

Progesterone concentrations in the bloodstream rise throughout pregnancy: It is, without a doubt, an important component of pregnancy maintenance. One of the primary mechanisms of progesterone activity in maintaining pregnancy is the cessation of myometrial contractions, which is ascribed to progesterone's relaxant effect on myometrial strips. ${ }^{6}$

Therefore, the aim of this study was to compare the efficacy of vaginal progesterone and cerclage in preventing preterm birth.

\section{PATIENTS AND METHODS}

This study was a prospective cohort randomized clinical study that was conducted on 120 pregnant 
females with singleton gestation from12-16 weeks. They were at high risk of PTB as those with history of prior spontaneous preterm labor, sonographic cervical length less than $25 \mathrm{~mm}$ in mid trimester or women with certain abnormalities of the uterus for instance, septate, unicornate, or bicornate uteri. They were divided into: 60 cases that were prescribed vaginal progesterone $(400 \mathrm{mg}$ daily at night from the $16^{\text {th }}$ week till rupture of membranes or delivery) and the remaining 60 cases underwent cervical cerclage. They were all recruited from the outpatient clinics at Al -Hussien university Hospital and Kafr EL- Sheikh General Hospital during the period from March 2020 till December 2020.Written consents were obtained from the patients.

Exclusion criteria: Multiple gestations, fetal chromosomal anomalies, intrauterine growth restriction, any fetal infection, and women who were already receiving an intervention before randomization to our interventions of interest were all excluded from this study.

The elected patients were subjected to detailed history taking, complete general, abdominal examination and ultrasonographic examination using a 3.5- 5-MHz transabdominal probe. After voiding, transvaginal scan was performed to measure the cervical length that was assessed by a $5-9 \mathrm{MHz}$ transvaginal probe. Then group I received vaginal progesterone from the 16th week till rupture of membranes or delivery, and Group underwent cervical cerclage (McDonald operation)

A purse string stitch was used to cinch the cervix shut; the cervix stitching involved a band of suture at the upper part of the cervix followed by postoperative antibiotics. The stitch was generally removed around the $37^{\text {th }}$ week of gestation or earlier if needed.

Then after intervention cases were followed up till parturition through routine antenatal care and any case developed IUGR were excluded from this study. Serial transabdominal ultrasound examinations were done to monitor AFI and fetus growth

All women received antenatal corticosteroids (Dexamethasone $6 \mathrm{mg}$ bidaily for 48 hours) before 36 weeks of gestation. The primary outcome was cases that completed 37 weeks of gestation in both groups.

Statistical analysis: Statistical analyses of data were done utilizing SPSS version 23. Shapiro-Wilks test was used to test normal distribution of variables. Numerical data were expressed as mean \pm standard deviation or median and range. Categorical data were summarized as percentages. The significance for the difference between groups was determined by using two-tailed Student's t test. Also Qualitative variables were assessed by chi-squared $\chi 2$ test. The probability (P) values of $\leq 0.05$ were considered statistically significant indicated. Mann whitney test was used to compare data that were not normally distributed.

\section{RESULTS}

Overall, 120 pregnant women at high risk of preterm birth who were chosen from the outpatient clinics at Al -Hussien university hospital and Kafr EL- Sheikh
General hospital during the period of research from March 2020 to December 2020. They all had singleton pregnancy with gestational age at the first antenatal visit of 12-16 weeks. Additionally, they had history of previous spontaneous preterm labor, and they all presented with sonographic cervical length $<25 \mathrm{~mm}$ in mid trimester. They were divided into 2 groups: Group (I) that included 60 cases received vaginal progesterone supplementation and Group (II) that included 60 cases were having a cervical cerclage. Nine cases had dropped out from the present study due to incomplete follow up. The final analysis of the results included only 111 women who completed the study.

The mean age was $26.07 \pm 3.7$ years in group (I) and $26.46 \pm 3.6$ years in group (II). There were no statistically significant differences in the mean age of both studied groups $(\mathrm{P}=0.574)$. Also, these results indicated that there was no statistically significant difference between all studied groups according to body mass index, mean cervical length, and parity $(\mathrm{P}>0.05)$ (Table1).

Additionally, the present study showed that there was no statistically significant difference between the two studied groups regarding previous history of preterm prelabour rupture of membranes (PPROM), preterm labour, and abortion $(\mathrm{P}>0.05)$. The present study indicated that cerclage, compared with vaginal progesterone treatment, significantly increased the rates of cesarean delivery ( $75 \%$ versus $63.6 \%$ ) but without significance difference $(\mathrm{P}=0.194)$. It was observed that the mean gestational age improved in the cerclage groups by about 3.92 days The gestational age at delivery was higher in the cerclage group $(36.32 \pm 2.12$ weeks) than that in the progesterone group (35.76 \pm 2.33 weeks), but without significant difference $(\mathrm{P}=0.190)$.

Considering neonatal birth weight, it was $2185.9 \pm 314.2$ in women who received vaginal progesterone compared to $2305.8 \pm 234.6$ in women who underwent cerclage; with $\mathrm{P}=$ value $=0.025$. In women who received vaginal progesterone, 44 (80\%) of newborns had weight less than $2.5 \mathrm{~kg}$ and remaining babies (20\%) were more than $2.5 \mathrm{~kg}$ weight whereas $76.8 \%$ of newborns to women who underwent cerclage had weight less than $2.5 \mathrm{~kg}$, and $23.2 \%$ were of weight more than $2.5 \mathrm{~kg}$. The current study showed that there was no significant difference between distribution of studied groups regarding neonatal birth weight $(\mathrm{P}=0.681)$ (Table1).

As regard neonatal outcome of the current delivery, the overall morbidity was shown in 22 cases (19.8\%) and mortality was $5(4.5 \%)$. Causes of mortality was very low birth weight $(<2500 \mathrm{~g})$ in $5(4.5 \%)$ babies; 3 of those five babies also had sepsis and the other 2 $(1.8 \%)$ had died due to lower gestational age of 30 weeks. Furthermore, the number of neonates admitted to the NICU was significantly lower in the cerclage group than that in the progesterone group $(\mathrm{P}<0.001)$.

In addition, the mean Apgar score was higher in the cerclage group than that in the progesterone groups (7.79 vs. 7.72). This results showed that the difference in the Apgar score was not statistically 
significant between the progesterone and the cerclage groups $(\mathrm{P}=0.809)$ (Table1).

\begin{tabular}{|c|c|c|c|}
\hline Variable $\quad$ Groups & $\begin{array}{c}\text { Group(I) } \\
(\mathbf{n}=55)\end{array}$ & $\begin{array}{c}\text { Group(II) } \\
(\mathbf{n}=56)\end{array}$ & P-value \\
\hline Age (Year) & $26.07 \pm 3.7$ & $26.46 \pm 3.6$ & 0.574 \\
\hline BMI at enrollment & $26 \pm 4.91$ & $27.11 \pm 4.73$ & 0.229 \\
\hline Cervical length (mm) & $21.82 \pm 2.29$ & $21.59 \pm 1.84$ & 0.562 \\
\hline Parity & $1.27 \pm 1.09$ & $1.26 \pm 1.15$ & 0.982 \\
\hline $\begin{array}{l}\text { Gestational age at delivery } \\
\text { (weeks) }\end{array}$ & $35.76 \pm 2.33$ & $36.32 \pm 2.12$ & 0.190 \\
\hline $\begin{array}{l}\text { Mode of delivery. } \\
\text { Vaginal } \\
\text { Cesarean section }\end{array}$ & $\begin{array}{l}20(36.4 \%) \\
35(63.6 \%)\end{array}$ & $\begin{array}{l}14(25 \%) \\
42(75 \%)\end{array}$ & 0.194 \\
\hline $\begin{array}{l}\text { Previous history of preterm } \\
\text { prelabour rupture of } \\
\text { membrane (PPROM) } \\
\text { No } \\
\text { Yes }\end{array}$ & $\begin{array}{l}45(81.8 \%) \\
10(18.2 \%)\end{array}$ & $\begin{array}{l}52(92.9 \%) \\
4(7.1 \%)\end{array}$ & 0.08 \\
\hline $\begin{array}{l}\text { Previous history of Preterm } \\
\text { labour } \\
\text { None } \\
\quad \mathbf{1 - 2} \\
\mathbf{3}\end{array}$ & $\begin{array}{c}30(54.5 \%) \\
24(43.6 \%) \\
1(1.8 \%)\end{array}$ & $\begin{array}{c}34(60.7 \%) \\
22(39.3 \%) \\
0(0 \%)\end{array}$ & 0.630 \\
\hline $\begin{array}{l}\text { History of abortion } \\
\text { None } \\
1-2 \\
3-4\end{array}$ & $\begin{array}{c}39(70.9 \%) \\
16(29.1 \%) \\
0(0 \%)\end{array}$ & $\begin{array}{l}34(60.7 \%) \\
20(35.7 \%) \\
2(3.6 \%)\end{array}$ & 0.285 \\
\hline Birth weight [g] & $2185.9 \pm 314.2$ & $2305.8 \pm 234.6$ & $0.025^{*}$ \\
\hline $\begin{array}{l}\text { Neonatal outcome } \\
\text { Neonatal Mortality } \\
\text { Neonatal Sepsis } \\
\text { Neonatal ICU more } 2 \\
\text { weeks } \\
\begin{array}{l}\text { Respiratory distress } \\
\text { syndrome (RDS) }\end{array}\end{array}$ & $\begin{array}{c}4(7.3 \%) \\
4(7.3 \%) \\
27(49.1 \%) \\
9(16.4 \%)\end{array}$ & $\begin{array}{c}1(1.8 \%) \\
1(1.8 \%) \\
10(17.9 \%) \\
9(16.1 \%)\end{array}$ & $\begin{array}{c}0.206 \\
0.206 \\
<0.001^{*} \\
0.967\end{array}$ \\
\hline Apgar score & $7.72 \pm 1.2$ & $7.79 \pm 1.33$ & 0.809 \\
\hline
\end{tabular}

Table 1: Demographic data and biochemical parameters of both studied groups.

Values are expressed as mean \pm standard deviation or $\mathrm{n}(\%)$ unless otherwise specified

BMI — body mass index

$*: \mathrm{P} \leq 0.05, * *: \mathrm{P} \leq 0.01$.

\section{DISCUSSION}

The mean gestational age in those who got vaginal progesterone was (35.762.33 weeks), whereas it was (36.322.12 weeks) in those who had cerclage. The cerclage groups had a 3.92-day improvement in gestational age. The cerclage group had a greater gestational age at birth than the progesterone group, although the difference was not significant $(\mathrm{P}=$ $0.190)$.

The results revealed that $1.8 \%$ of cases were delivered at gestational age from 28 to 30 weeks, $8.1 \%$ of cases were delivered at gestational age from 30 to 32 weeks, $26.1 \%$ at more than 32 but less than 
37 weeks, $36 \%$ at 37 weeks, , and the remaining 27.9 $\%$ at more than 37 weeks of gestation. The current study showed that there was no significant difference between distribution of studied groups regarding gestational age at delivery $(\mathrm{P}=0.488)$. Thus the number of cases that reached term was $58.1 \%$ in cases of vaginal progesterone only \& $69.6 \%$ in cases of cerclage group.

Cervical cerclage, recognized to diminish the risk of PTB in roughly $20 \%$ in women with a history of spontaneous PTB and/or a short cervical length, is advocated by both the UK Royal and American Colleges of Obstetricians and Gynecologists. It acts through delivering mechanical support to a weakened cervix together with supporting the cervical mucosal plug guarding against ascending infection.?

Regarding outcome, Naim et al. ${ }^{8}$ found that each of vaginal progesterone per se (with $68 \%$ of cases had reached term) or cerclage per se (with $70 \%$ of cases reached term delivery) lowered the PTB risk significantly weighed against controls. Likewise, they stated that cerclage and vaginal progesterone combination ensued higher reduction of preterm labor (with $80 \%$ of cases delivered at term).

Our results were analogous also to study done by Alfirevic et al. ${ }^{9}$ as their results suggested equal effectiveness of both vaginal progesterone and cerclage for women with singleton pregnancy who have at least one prior PTB and a shortened cervical length via transvaginal ultrasonography.

O'Brien et al. ${ }^{10}$ carried out a descriptive cross sectional study over a 2 years period on patients having history of more than or equal 2 repeated midtrimester abortions and or preterm deliveries. They show up that after application of cervical cerclage; $73.7 \%$ of cases reached term delivery, $18.7 \%$ had PTB and $7.5 \%$ of them had miscarriages.

In line to that, Celen et al. ${ }^{11}$ also demonstrated that after cerclage $76 \%$ of cases delivered at term, $12 \%$ had preterm deliveries, and $10 \%$ had abortions.

In another study conducted by Conde-Agudelo et al. 12 women allocated to receive vaginal progesterone had significantly lower risk of preterm birth less than 33 weeks than those allocated to placebo (or no treatment). In addition, vaginal progesterone was associated with a significant reduction in the risk of PTB less than, 32, 33, 34, and 35 weeks of gestation.

Also, our results revealed that in the $2(1.8 \%)$ women with a lower gestational age of $28-30$ weeks at delivery, the neonatal morbidity was $2(100 \%)$ \& mortality was $2(100)$ percent. In $9(8.1 \%)$ of cases whose gestational age was slightly better 30-32 weeks morbidity was $4(44.44 \%)$ and mortality was 1 (11.1\%) percent. Further in case of $29(26.1 \%)$ women having gestational age 32-35 week the morbidity was $6(20.7 \%)$ and mortality was $0(0 \%)$ percent. In addition, the percentage of morbidity and mortality among women with gestational age ranged from 35 to 37 weeks was $12.5 \%$ and $5 \%$ respectively. After completion of 37 weeks, the morbidity rate was $(16.1 \%)$.
There was statistically significant difference between the both studied groups regarding mean birth weight as it was $2185.9 \pm 314.2$ in women who received vaginal progesterone compared to $2305.8 \pm 234.6$ in women who underwent cerclage; with $\mathrm{P}=$ value $=0.025)$ this may be due to higher percentage of term pregnancy in cerclage group than progesterone one. Also the mean Apgar score was not statistically significant between both groups $(\mathrm{P}=0.809)$.

Romero et al. ${ }^{13}$, who assembled individual data from five prior studies, found that vaginal progesterone made improvement in a multitude of outcomes and showed that vaginal progesterone significantly had resulted in reduction of the risk of fetal death by $34 \%$ and preterm birth $\leq 34$ weeks of gestation amongst women with a singleton gestation and a midtrimester $\mathrm{CL} \leq 25 \mathrm{~mm}$.

In the meta-analysis of data from the OPPTIMUM study; the decline in preterm outcome was allied to a drop in the rate of PTB $\leq 34$ weeks of gestation rather than diminution of fetal death since vaginal progesterone had no influence on the risk of this adverse outcome. ${ }^{14}$

In prior studies for progesterone as an effective intervention to prevent preterm birth. Including the PROGRESS Study. ${ }^{15}$ Several studies assessed PV progesterone in women with previous preterm birth and reported PTB $<37$ weeks (the PROGRESS Study did not report PTB $<34$ weeks), with a pooled effect size of 0.43 (95\% CrI 0.23-0.74, Moderate quality of evidence), although with substantial heterogeneity. Three studies had positive, statistically significant effects with progesterone Majhi et al. ${ }^{16}$, Cetingoz et al. ${ }^{17}$ and Azargoon et al. ${ }^{18}$, while the remaining two, which account for $86 \%$ of the sample, centred on the null effect O'Brien et al. ${ }^{19}$ and Crowther et al. ${ }^{15}$. One possible explanation is publication bias.

Jarde et al. ${ }^{20}$ compared vaginal progesterone suppositories versus vaginal gel or pessary in women with former PTB and reported that applying vaginal suppositories had significant, positive results, compared to vaginal gel or pessary that did not produce these findings.

A subgroup analysis by dose of progesterone $(\leq 200$ against vs. >200 mg/day) revealed a statistically significant differences between the former mentioned formulas in favor of the greater doses. ${ }^{18}$

\section{CONCLUSION}

Both vaginal progesterone as well as cervical cerclage had a significant beneficial impact in opposition to preterm delivery and improving perinatal consequences among the high-risk singleton pregnant ladies with former spontaneous PTB, and a mid-trimester short cervix via ultrasound. The preemptive effect of cerclage was to some extent superior than that of vaginal progesterone but progesterone had also assuring results.

Further research is required to explore vaginal progesterone's heterogeneity of results and to confirm the reduction in neonatal death with it and randomly investigate combinations of both therapies. 
Ethical approval: Approval of ethical committee was obtained from quality education assurance Unit, Faculty of Medicine, Al-Azhar University Egypt.

\section{REFERENCES}

1. Cheung KW, Seto MY and Ng EH. Early universal use of oral progesterone for prevention of preterm births in singleton pregnancy (SINPRO study): protocol of a multicenter, randomized, double-blind, placebo-controlled trial. Trials, 2020; 21(1): 121-6.

2. Algameel A, Elhawary M, Amin S, et al. Outcome of late preterm newborns in Upper Egypt. Egyptian Pediatric Association Gazette, 2020; 68: 1-11.

3. Thain S, Yeo GS, Kwek K, et al. Spontaneous preterm birth and cervical length in a pregnant Asian population. PloS one, 2020; 15(4): 0230125.

4. Biggio JR. Current Approaches to Risk Assessment and Prevention of Preterm BirthA Continuing Public Health Crisis. Ochsner Journal, 2020; 20(4): 426-33.

5. Enakpene CA, Dijeh FC, Vengalil ET, et al. An Overview of The Role of Cerclage In The Prevention of Spontaneous Preterm Birth. Journal of Reproductive Medicine Gynaecology and Obstetrics, 2020; 5: 48-55.

6. Norman JE. Progesterone and preterm birth. International Journal of Gynecology and Obstetrics, 2020; 150(1): 24-30.

7. Shor S, Zimerman A, Maymon R, et al. Combined therapy with vaginal progesterone, Arabin cervical pessary and cervical cerclage to prevent preterm delivery in high-risk women. The Journal of Maternal-Fetal \& Neonatal Medicine, 2019; 19: 1-5.

8. Naim RM, Samie MA and Elkatatny $\mathrm{HH}$ Vaginal Progesterone versus Cervical Cerclage or Both for Prevention of Preterm Delivery. The Egyptian Journal of Hospital Medicine, 2018; 71(5): 3206-10.

9. Alfirevic Z, Owen J and Carreras Moratonas E, Sharp AN, Szychowski JM et al. Vaginal progesterone, cerclage or cervical pessary for preventing preterm birth in asymptomatic singleton pregnant women with a history of preterm birth and a sonographic short cervix. Ultrasound in Obstetrics \& Gynecology, 2013; 41(2): 146-51.

10. O'brien JM, Hill AL and Barton JR. Funneling to the stitch: an informative ultrasonographic finding after cervical cerclage. Ultrasound in Obstetrics and Gynecology: The Official Journal of the International Society of Ultrasound in Obstetrics and Gynecology, 2002; 20(3): 252-5.
11. Celen S, Simsek Y, Ozyer S, et al. Effectiveness of emergency cervical cerclage in patients with cervical dilation in the second trimester. Clinical and Experimental Obstetrics \& Gynecology, 2011; 38(2): 131-3.

12. Conde-Agudelo A, Romero R, El-Refaie W, et al. Vaginal progesterone decreases preterm birth and neonatal morbidity and mortality in women with a twin gestation and a short cervix: an updated meta-analysis of individual patient data. Ultrasound in Obstetrics \& Gynecology, 2017; 49(3): 303-14.

13. Romero R, Nicolaides K, Conde-Agudelo A, et al. Vaginal progesterone decreases preterm birth $\leq 34$ weeks of gestation in women with a singleton pregnancy and a short cervix: an updated meta-analysis including data from the OPPTIMUM study. I, 2016; 48(3): 308-17.

14. Norman JE, Marlow N, Messow CM et al. Vaginal progesterone prophylaxis for preterm birth (the OPPTIMUM study): a multicentre, randomised, double-blind trial. The Lancet, 2016; 387(10033): 2106-16

15. Crowther CA, Ashwood P, McPhee AJ, et al. Vaginal progesterone pessaries for pregnant women with a previous preterm birth to prevent neonatal respiratory distress syndrome (the PROGRESS Study): A multicentre, randomised, placebo-controlled trial. PLoS Medicine, 2017; 14(9): 1002390.

16. Majhi P, Bagga R, Kalra J, et al. Intravaginal use of natural micronised progesterone to prevent pre-term birth: a randomised trial in India. Journal of Obstetrics and Gynaecology, 2009; 29(6): 493-8.

17. Cetingoz E, Cam C, Sakallı $M$, et al. Progesterone effects on preterm birth in highrisk pregnancies: a randomized placebocontrolled trial. Archives of Gynecology and Obstetrics, 2011; 283(3): 423-9.

18. Azargoon A, Ghorbani R and Aslebahar F. Vaginal progesterone on the prevention of preterm birth and neonatal complications in high risk women: a randomized placebocontrolled double-blind study. International Journal of Reproductive Biomedicine, 2016; 14(5): 309-15.

19. O'brien JM, Adair CD, Lewis DF, et al. Progesterone vaginal gel for the reduction of recurrent preterm birth: primary results from a randomized, double-blind, placebo-controlled trial. Ultrasound in Obstetrics and Gynecology, 2007; 30(5): 687-96.

20. Jarde A, Lutsiv O, Beyene J, et al. Vaginal progesterone, oral progesterone, 17-OHPC, cerclage, and pessary for preventing preterm birth in at-risk singleton pregnancies: an updated systematic review and network metaanalysis. BJOG: An International Journal of Obstetrics \& Gynaecology, 2019; 126(5): 55667. 